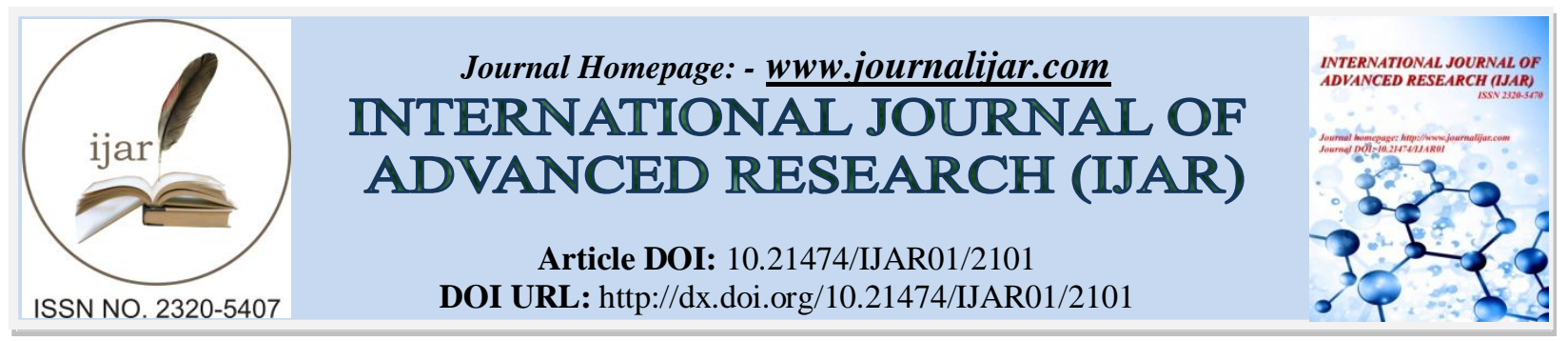

RESEARCH ARTICLE

\title{
SYNTHESIS AND CHARACTERIZATION OF ALUMINIUM DOPED ZnO NANOPARTICLES.
}

\author{
S. R. Brintha and M. Ajitha.
}

Department of Chemistry, Annai Velankanni College, Tholayavattam, Tamil Nadu, India.

\section{Manuscript Info}

Manuscript History

Received: 24 September 2016

Final Accepted: 26 October 2016

Published: November 2016

Key words:-

Nanoparticle , dopant, zinc oxide , aqueous solution, EDX

\begin{abstract}
$\mathrm{ZnO}$ nanoparticles were synthesized by aqueous solution method.The synthesized particles were characterized by XRD, SEM and EDX .The X-ray diffraction studies reveals that the synthesized $\mathrm{ZnO}$ nanoparticles have wurtzite structure and the particle size varies from 11 to $13 \mathrm{~nm}$. A change in morphology from hierarchical nanostructures in $\mathrm{ZnO}$ to nanorods after doping with aluminium has been observed. The Energy Dispersive X-Ray Diffraction Spectroscopy (EDX) reveals that the elemental composition of prepared samples and the incorporation of the $\mathrm{Al}$ ions into the $\mathrm{ZnO}$ lattice. The antibacterial activities of $\mathrm{ZnO}$ and $\mathrm{Al}$ doped $\mathrm{ZnO}$ nanoparticles were examined using the disc diffusion method against four pathogenic bacteria (Eschericia Coli , Klebsiella Pneumoniae , Bacillus Cereus, and Staphylococcus aureus)

Copy Right, IJAR, 2016,. All rights reserved.
\end{abstract}

\section{Introduction:-}

$\mathrm{ZnO}$ is a II-VI semiconductor with wide band-gap $(3.37 \mathrm{eV})$ and exciton binding energy $(60 \mathrm{meV})$ at room temperature. $\mathrm{ZnO}$ nanostructures can be synthesized into a variety of morphologies, including nanowires, nanorods, tetrapods, nanobelts, nanoflowers and nanoparticles [1]. It is an inexpensive and environmentally safe host material [2]. In addition to catalytic properties, metal oxide nanoparticles also exhibit electronic, optical and magnetic properties. In the few decades, metal oxide nanoparticles were extensively investigated due to their applications in the field of spintronics, photoelectronic, sensor, lasing devices and light emitting diodes, etc [3]. These remarkable properties make them to find many applications in the field of medicine, electronic devices and in many industries [4]. Zinc oxide has high biocompatibility and fast electric transfer kinetics, such phenomena encourage the use of this material as a bio membrane to immobilize and modify the biomolecules [5].

Nowadays, various routes have been used for the synthesis of $\mathrm{ZnO}$ nanomaterials, such as sol-gel synthesis, hydrothermal, solvothermal methods, micro emulsion method, precipitation, and physical vapor deposition [6]. Zinc oxide-soluble starch nano composites were synthesized using water as a solvent and soluble starch as a stabilizer and impregnated onto cotton fabrics to impart antibacterial and UV-protection functions. [7]. Zinc oxide, with its unique physical and chemical properties, such as high chemical stability, high electrochemical coupling coefficient, broad range of radiation absorption and high photo stability, is a multifunctional material [8].

$\mathrm{ZnO}$ nano powders doped with different ions such as $\mathrm{Al}, \mathrm{In}, \mathrm{Ga}$, etc. have improved electrical, optical, and catalytic properties. Among these, Al-doped $\mathrm{ZnO}$ (AZO) nanopowders are both conductive and transparent in the visible region and thus can be utilized in transparent conductive pastes [9]. The enhancement of conductivity makes $\mathrm{Al}^{3+}$ and $\mathrm{In}^{3+}$ doped $\mathrm{ZnO}$, a promising candidate for optoelectronic applications [10]. Inorganic nanocrystalline metal oxides such as $\mathrm{ZnO}$ are particularly interesting because they can be prepared with extremely high surface areas, and 
are more suitable for biological applications. $\mathrm{ZnO}$ is widely used to treat a variety of skin conditions, in products such as baby powder, barrier creams to treat diaper rashes and in calamine cream, antidandruff shampoos and antiseptic ointments [11].The inorganic antibacterial materials have advantages over organic antibacterial material that the former shows superior durability, less toxicity and greater selectivity and heat resistance [12]. Some researchers have shown the performance of $\mathrm{ZnO}$ nanoparticles in degradation of some organic compounds, antibacterial effect and killing human cancer cells [13]. Zinc oxide nanoparticles are known to be one of the multifunctional inorganic nanoparticles with effective antibacterial activity. Antibacterial and antifungal activities of $\mathrm{ZnO}$ nanoparticles are observed even at very lower concentrations and also the antifungal activity does not affect soil fertility compared to the conventional antifungal agents [14].

\section{Materials and Methods:- \\ Materials:-}

Zinc acetate, Aluminiun nitrate, Trisodium citrate, Ammonia solution, Sodium hydroxide. All the reagents used were analytical grade, obtained from Merck (Indian) Ltd, and used without further purification.

\section{Preparation of ZnO nanoparticles:-}

$\mathrm{ZnO}$ nanoparticle was synthesized by aqueous solution method using zinc acetate as a precursor. The entire process was carried out with double distilled water. About $2.1 \mathrm{~g}$ of zinc acetate was dissolved in $200 \mathrm{ml}$ of double distilled water along with varying amounts of aluminium nitrate (1.5-2.5\%).After 10 minutes of magnetic stirring about $1.5 \mathrm{~g}$ of trisodium citrate in $10 \mathrm{ml}$ water and $4.2 \mathrm{ml}$ of $25 \%$ ammonia solution are added. Then, $20 \mathrm{ml}$ of $2 \mathrm{M} \mathrm{NaOH}$ solution was added drop wise with vigorous stirring. The temperature of the contents are raised to $80^{\circ} \mathrm{C}$ and kept at this temperature for about 6 hours. The contents are centrifuged and the precipitate was washed with distilled water and then dried at $60^{\circ} \mathrm{C}$ to get aluminium doped $\mathrm{ZnO}$ nanoparticles.

Undoped $\mathrm{ZnO}$ was synthesized with a similar procedure except the addition of doping materials.

\section{Characterization of synthesized nanoparticles:-}

The structural properties including structure and crystalline size of the samples are determined by $\mathrm{x}$-ray diffractometer. The powder $\mathrm{x}$-ray diffraction (XRD) was performed using automated $\mathrm{x}$-ray diffractometer (XPERTPRO Philips system ) operating $\mathrm{CuK}_{\alpha}$ at wavelength $1.54056 \AA$. The average crystallite size (D) has been calculated using Schrerer's relation $D=K \lambda / \beta \cos \theta$, where the constant $K$ is taken to be $0.94, \lambda$ is the wavelength of $\mathrm{X}$-ray used and $\beta$ the full width of half maximum (FWHM). The morphology of the zinc oxide samples were characterized by scanning electron microscope (SEM) equipped with an energy dispersive X-ray spectrometer (EDX) to analyse the elemental composition of the synthesized materials. The FT-IR spectra was recorded using a SHIMADZU instrument. Antimicrobial activities of the samples are determined by well diffusion method. Four pathogenic bacterial strains namely Escherichia coli, Klebsiella pneumonia, Bacillus cereus and Staphyloccocus aureus are used in this investigation.

\section{Results and discussion:-} X-ray diffraction analysis:-

Structural parameters of zinc oxide nanoparticles are calculated from the XRD pattern.

Fig: 1(a) shows seven diffraction peaks at $2 \theta$ values of $31.6811^{0}, 34.3596^{\circ}, 36.1769^{\circ}, 47.4835^{\circ}, 56.5269^{0}, 62.8115^{0}$ and $67.9130^{\circ}$. The peaks are identified to originate from (100), (002), (101), (102), (110), (103) and (112) planes. Based on the Schrerer equation the average crystallite sizes of the nanoparticles are observed as $13 \mathrm{~nm}$. All the peaks are indexed and found to be well matched to wurtzite structure of $\mathrm{ZnO}$ having hexagonal phase, which is in good agreement with the standard JCPDS (Card No. 36-1451).

Fig: 1(b) shows seven diffraction peaks at $2 \theta$ values of $31.5972^{0}, 34.4634^{0}, 36.1142^{0}, 46.7427^{0}, 56.4519^{0}, 61.4925^{0}$ and $67.8332^{\circ}$. The peaks are identified to originate from (100), (002), (101), (102), (110), (103) and (112) planes. Based on the Schrerer equation the average crystallite sizes of the nanoparticles are observed as $11 \mathrm{~nm}$.

Fig: 1 (c) shows seven diffraction peaks at $2 \theta$ values of $31.8818^{0}, 34.2000^{\circ}, 36.4000^{\circ}, 47.8697^{0}, 56.5628^{0}, 63.0000^{0}$ and $68.2000^{\circ}$. The peaks are identified to originate from (100), (002), (101), (102), (110), (103) and (112) planes. Based on the Scherrer equation the average crystalline sizes of the nanoparticles are observed as $12 \mathrm{~nm}$. 
Fig: 1(d) shows seven diffraction peaks at $2 \theta$ values of $31.6811^{0}, 33.4524^{0}, 35.2516^{0}, 46.9672^{0}, 55.5432^{0}, 61.4356^{0}$ and $67.8976^{\circ}$. The peaks are identified to originate from (100), (002), (101), (102), (110), (103) and (112) planes. Based on the Scherrer equation the average crystalline sizes of the nanoparticles are observed as $13 \mathrm{~nm}$.
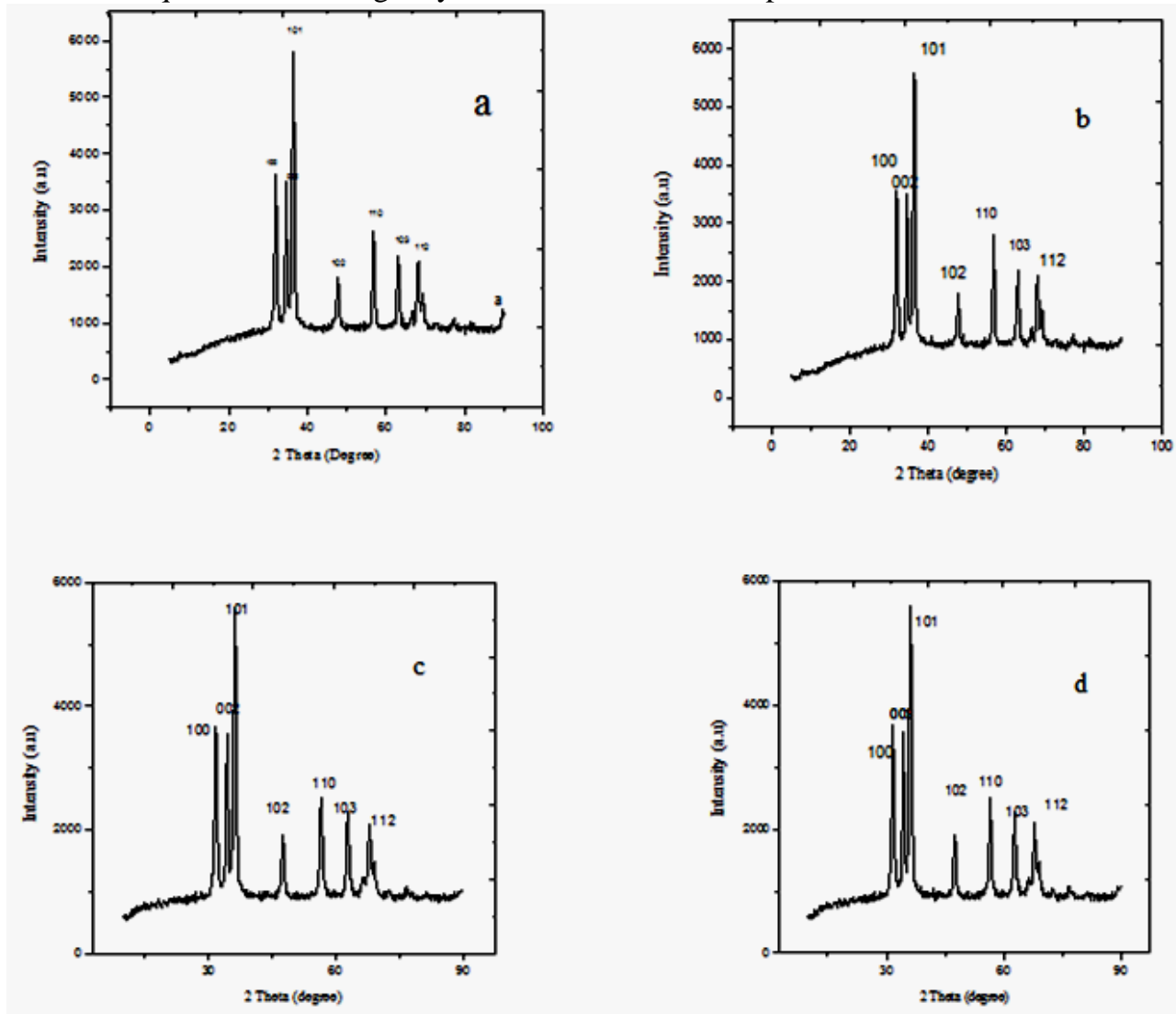

Fig: 1(a):- XRD patterns of undoped $\mathrm{ZnO}$, (b) $\mathrm{Al}$ (1.5\%) doped, (c) $\mathrm{Al}(2 \%)$ doped and (d) $\mathrm{Al}(2.5 \%)$ doped $\mathrm{ZnO}$ nanoparticles by aqueous solution method.

\section{SEM analysis:-}

Scanning electron microscopy (SEM) was employed to analyse the morphology and the growth features of prepared nanoparticles.

Fig: 2:- shows the SEM images of pure zinc oxide and Aluminium doped zinc oxide nanoparticles. The images show change in morphology of particles from hierarchical nanostructures in pure zinc oxide to distorted hierarchical nanostructures $\left(\left[\mathrm{Al}^{3+}\right]=1.5 \%\right)$ and then to rods $\left(\left[\mathrm{Al}^{3+}\right]=2.5 \%\right)$.

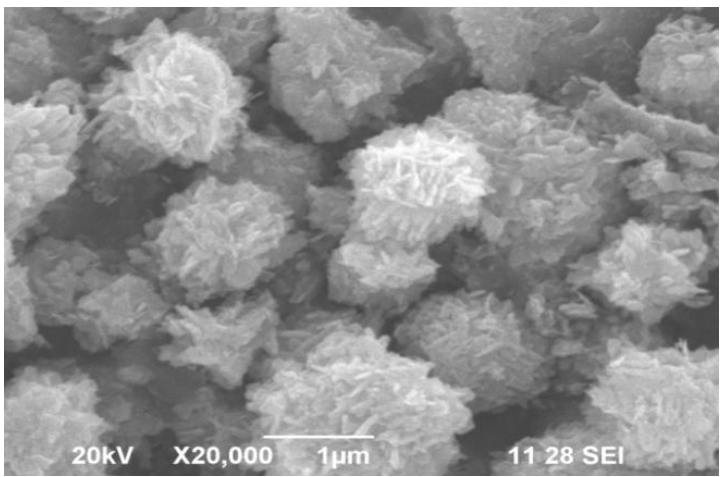

a)

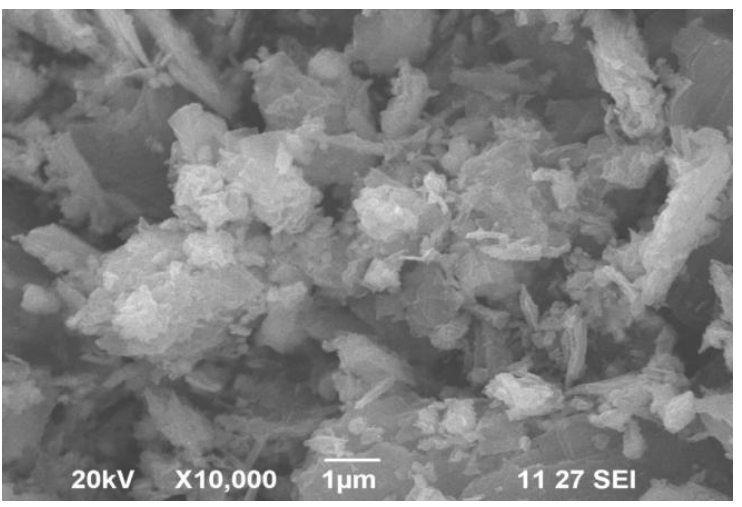

b) 


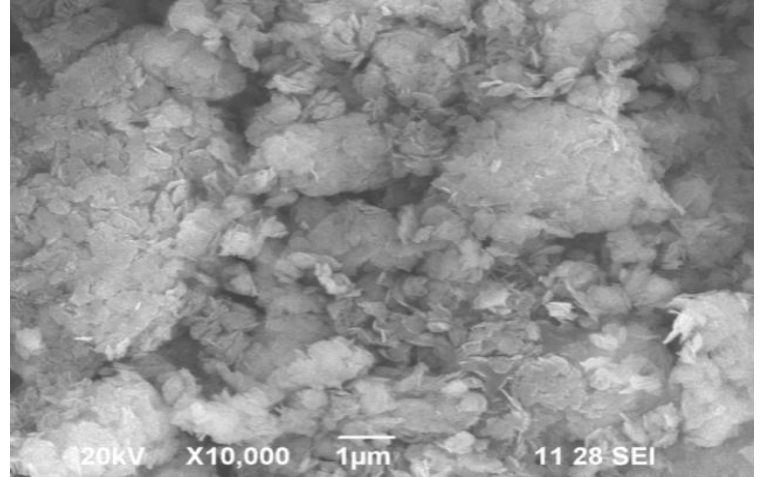

c)

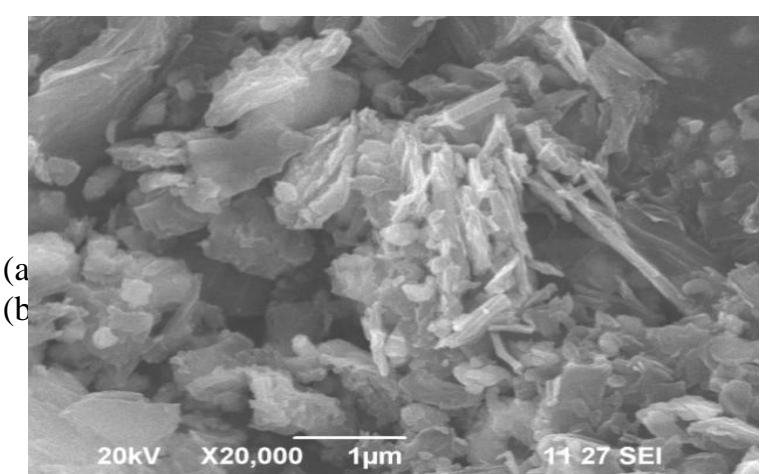

d)

Fig: 2 (a) SEM image of undoped ZnO, (b) SEM image of Al (1.5\%), (c) SEM image of Al (2\%) and (d) SEM image of $\mathrm{Al}(2.5 \%)$ doped $\mathrm{ZnO}$ nanoparticles.

\section{Energy Dispersive X-Ray Diffraction Spectroscopy (EDX) :-}

The elemental composition of the undoped $\mathrm{ZnO}$ and $\mathrm{Al}$ ion doped $\mathrm{ZnO}$ nanoparticles, at different concentrations were carried out by EDX spectroscopy.

Fig: 3(a) shows the EDX spectrum of undoped $\mathrm{ZnO}$ nanoparticles. The strong peaks observed in the spectrum related to $\mathrm{Zn}$ and oxygen. The prepared $\mathrm{ZnO}$ nanoparticles have atomic percentage of 40.90 of $\mathrm{Zn}$ and 59.10 of oxygen. This confirmed the formation of $\mathrm{ZnO}$ nanoparticles. In fig: 3(b) The prepared Al-doped (1.5\%) zinc oxide nanoparticles have atomic percentage at 17.73 of $\mathrm{Zn}, 75.27$ of oxygen and 7 of $\mathrm{Al}$. In fig: 3(c) Al (2\%) doped The prepared $\mathrm{Al}(2 \%)$ doped zinc oxide nanoparticles have atomic percentage at 77.65 of oxygen, 14.58 of $\mathrm{Zn}$, and 7.77 of Al. In fig: 3(d) $\mathrm{Al}(2.5 \%)$ doped zinc oxide nanoparticles have atomic percentage at $11.10 \mathrm{of} \mathrm{Zn}, 78.91$ of oxygen and 9.99 of $\mathrm{Al}$. This confirmed the doping of $\mathrm{Al}$ ion into the zinc oxide lattice.

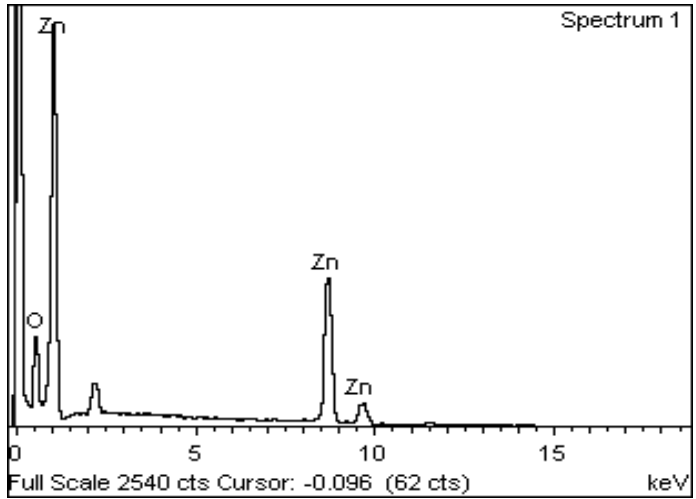

a)

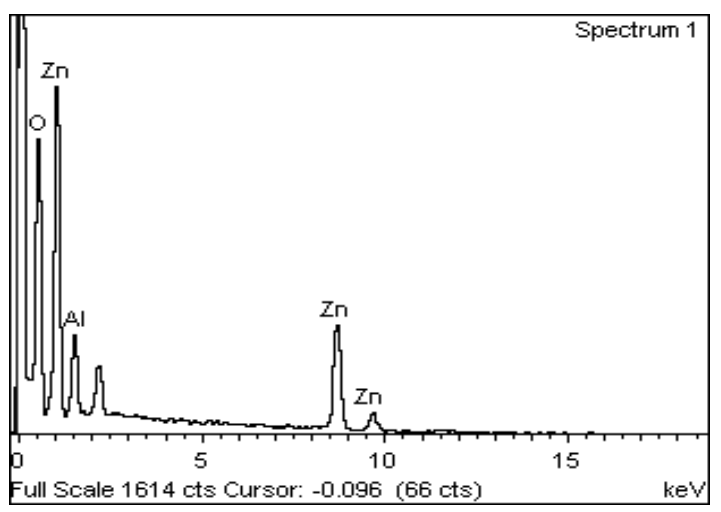

c)

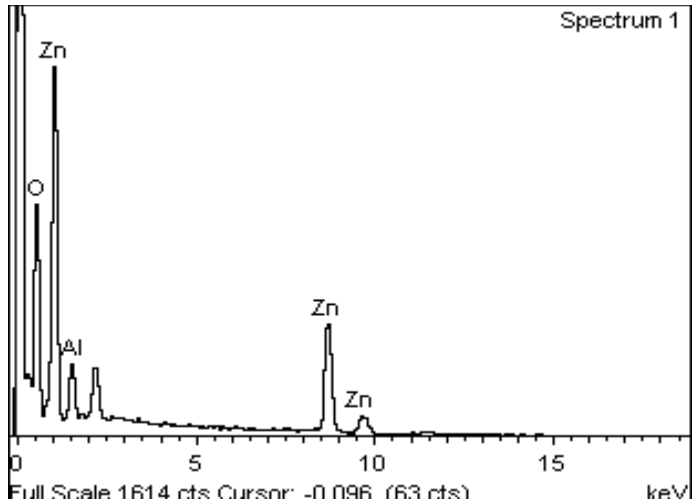

b)

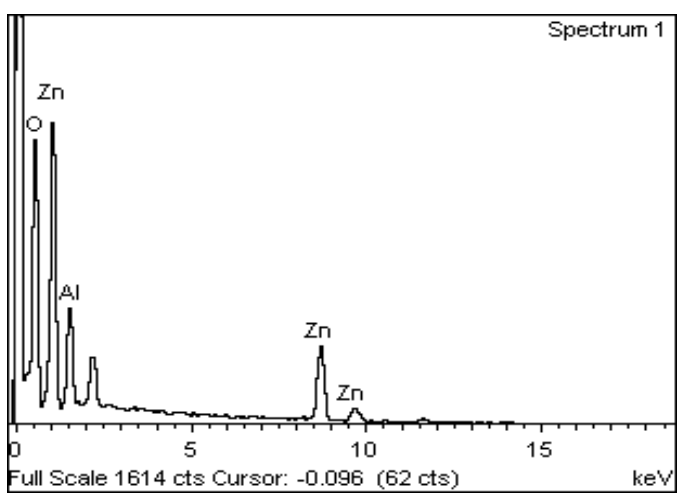

d) 
Fig: 3 (a):- Energy dispersive $\mathrm{x}$-ray diffraction spectrum of undoped $\mathrm{ZnO}$ (b) Al-doped (1.5\%) $\mathrm{ZnO}$ (c) Al-doped (2\%) $\mathrm{ZnO}$ and (d) Al-doped (2.5\%) $\mathrm{ZnO}$ nanoparticles.

Table 1:- The atomic content of the different type of nanoparticles obtained from the EDX measurements

\begin{tabular}{|l|l|l|l|}
\hline \multirow{2}{*}{ Type of nanoparticles } & \multicolumn{3}{|c|}{ EDX results } \\
\cline { 2 - 4 } & Oxygen (at\%) & Aluminium (at\%) & Zinc (at\%) \\
\hline Undoped $\mathrm{ZnO}$ & 59.10 & - & 40.90 \\
\hline $1.5 \% \mathrm{Al}$ doped $\mathrm{ZnO}$ & 75.27 & 7.0 & 17.73 \\
\hline $2 \% \mathrm{Al}$ doped $\mathrm{ZnO}$ & 77.65 & 7.77 & 14.58 \\
\hline $2.5 \% \mathrm{Al}$ doped $\mathrm{ZnO}$ & 78.91 & 9.99 & 11.10 \\
\hline
\end{tabular}

\section{Antibacterial activity:-}

Antibacterial activities of $\mathrm{ZnO}$ nanoparticles, were examined using the disc diffusion method. Antibacterial activities were studied against four pathogenic bacteria (Eschericia Coli, Klebsiella Pneumoniae, Bacillus Cereus, and Staphylococcus aureus).The ranges of bacterial strains for undoped and doped $\mathrm{ZnO}$ nanoparticles were shown in table 2. Al doped zinc oxide nanoparticles shows more activity in all four pathogenic bacteria than undoped zinc oxide nanoparticles.

Table 2:- Various ranges of bacterial strains for undoped and aluminium doped $\mathrm{ZnO}$ nanoparticles from aqueous solution method.

\begin{tabular}{|l|l|l|l|}
\hline \multirow{2}{*}{ S. No } & \multirow{2}{*}{ Name of bacteria } & \multicolumn{2}{|l|}{ Inhibition zone for samples } \\
\cline { 3 - 4 } & & Undoped ZnO & Al doped ZnO \\
\hline 1 & Escherichia Coli & 9 & 13 \\
\hline 2 & Klebsiella Pneumoniae & 8 & 12 \\
\hline 3 & Bacillus Cereus & 8 & 12 \\
\hline 4 & Staphylococcus Aureus & 8 & 12 \\
\hline
\end{tabular}

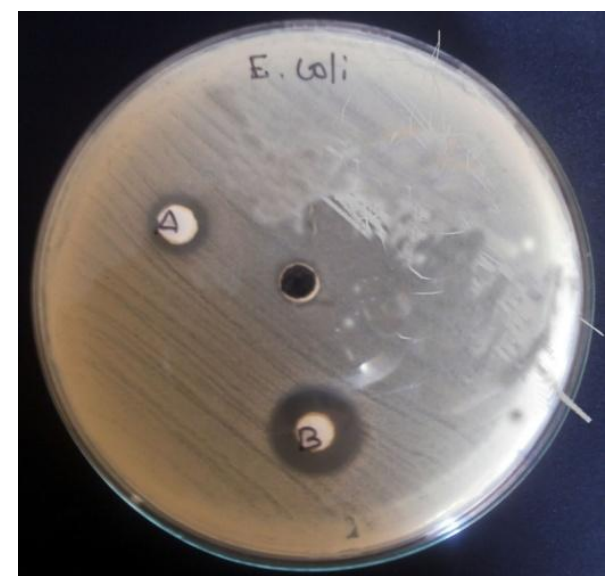

a)

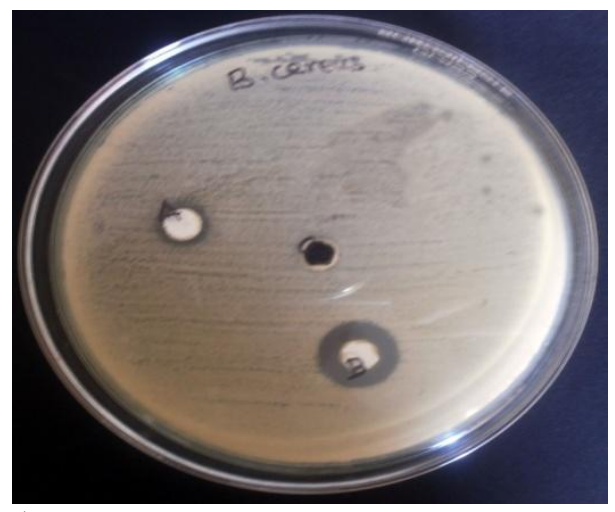

c)

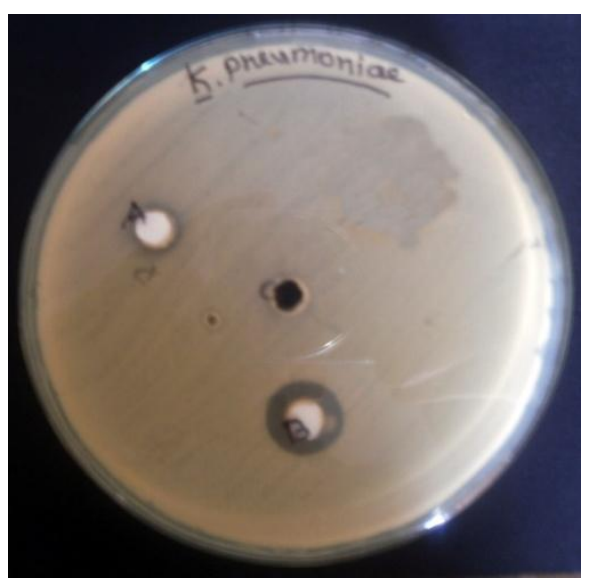

b)

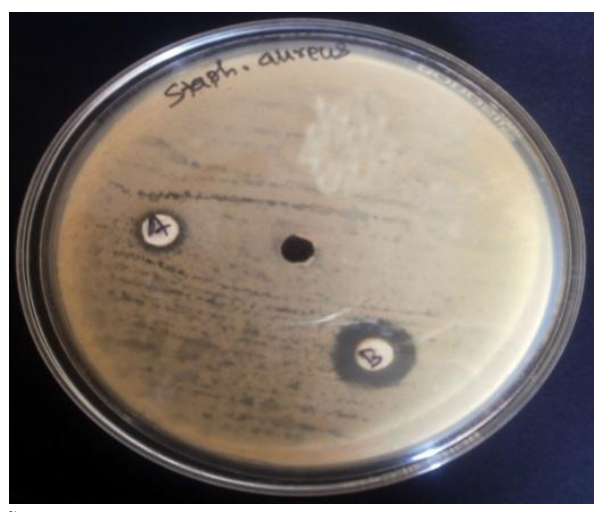

d) 
Fig. 4 (a):- Antibacterial activity against E-Coli, (b) Bacillus Cereus, (c) Klebsiella Pneumoniae and (d) Staphylococcus Aureus [A- undoped $\mathrm{ZnO}, \mathrm{B}-\mathrm{Al}$ doped $\mathrm{ZnO}$ ]

\section{Conclusion:-}

Zinc oxide nanoparticles and Aluminium doped $\mathrm{ZnO}$ doped nanoparticles are prepared by aqueous solution method and the prepared nanoparticles are characterized by XRD, SEM, EDX. The crystalline size of the prepared nanoparticles determined by Debye-shrerer's equation was found to be in the nanometer range and show preferred growth orientation along (101) plane. All the nanoparticles showed wurtzite structure. The surface morphology of the $\mathrm{ZnO}$ nanoparticles characterized by SEM analysis suggested different morphological structures. Chemical purity and stoichiometry of the samples were investigated by EDAX Spectroscopy, inorder to confirm the presence of $\mathrm{Zn}, \mathrm{O}$, and $\mathrm{Al}$ ions in the material.

The synthesized $\mathrm{ZnO}$ nanoparticles are moderately sensitive to antibacterial organisms. Al doped zinc oxide nanoparticle is found to be more active against four pathogenic bacteria (Eschericia Coli, Klebsiella Pneumoniae, Bacillus Cereus, and Staphylococcus aureus). Thus it can be used for further medicinal applications.

\section{References:-}

1. PRAUS Petr, TOKARSKY Jonas SVOBODA Ladislav, "Contribution to synthesis of $\mathrm{ZnO}$ nanoparticles by uv irradiation-assisted precipitation", (2015)

2. Y. Abdollahi, A.H. Abdullah, Z. Zainal and N.A. Yusof, "Synthesis and characterization of Manganese doped ZnO nanoparticles", International Journal of Basic \& Applied Sciences, Vol: 11, $44-50$ (2011).

3. P.D. Sahare, Vipin Kumar, "Optical and Magnetic properties of $\mathrm{Cu}$-doped $\mathrm{ZnO}$ Nanoparticles", International journal of Innovative Technology and Exploring Engineering (IJITEE), ISSN: 2278-3075, Volume-3, (2013).

4. Sowbhagya and S. Ananda, "Synthesis and Characterization of Mo-Doped $\mathrm{ZnO}$ Nanoparticles by Electrochemical Method: Photodegradation Kinetics of Methyl Violet Dye and Study of Antibacterial Activities of Mo-Doped ZnO Nanoparticles", International Journal of Nanomaterials and Biostructures, ISSN 2277-3851 , (2015)

5. Riyadh M. Alwan, Quraish A. Kadhim, Kassim M. Sahan, Rawaa A. Ali, Roaa J. Mahdi, Noor A. Kassim, Alwan N. Jassim, "Synthesis of Zinc Oxide Nanoparticles via Sol - Gel Route and Their Characterization", Nanoscience and Nanotechnology 2015, 5(1): 1-6

6. Kolekar T.V, Yadav H.M, Bandgar S.S, Raskar A.C, Rawal S.G, Mishra G.M, "Synthesis by Sol-gel method and characterization of ZnO nanoparticles", Indian Streams Research Journal, Vol:2, (2011).

7. Akash Sharmal and Purnima Swaroop Khare, "Synthesis and characterization of zinc oxide Nano-particles by hydrothermal method", Progress In Science and Engineering Research Journal ISSN 2347-6680, Vol.03, (2015).

8. Faranak Asgari and Fatemeh Rashedi, "Synthesis of $\mathrm{ZnO}$ nanoparticles", Indian Journal of Fundamental and Applied Life Sciences, ISSN: 2231-6345, Vol. 5, pp. 809-811, (2015).

9. Wasi Khan, Z.A.Khan, A.A saad, S.Shervani, A. Saleem, A.H Nagvi "Synthesis and Characterisation of Al doped ZnO nanoparticles", International Journal of Modern physics, Vol:22, 630-636. (2013)

10. Nural Syahiah Sabri, Ahmad Kamal Yahya, Nur Aimi Jani, Mohammad Kamal Harun and Mahesh Kumar Talari, "Effect of aluminium and indium doping on structural and optical properties of $\mathrm{ZnO}$ nanoparticles prepared by mechanochemical processing", International Journal of the Institute of Materials Malaysia (IJIMM), Vol: 1 (2013).

11. K.Ravinchandrika, P.Krianmayi and R.V.S.S.N Ravikumar,"Stnthesis, characterization and antibacterial activity of ZnO nanoparticles", International Journal of Pharmacy and Pharmaceutical Sciences, ISSN -09751491. Vol:4, (2012)

12. Vani C, Sergin G.K and Annamalai A, "A study on the effect of Zincoxide nanoparticles in staphycoccus aures", Internatoinal Journal of Pharma and Bio Sciences Vol: 2, (2011)

13. Ghaffarian, Hamid Reza, Saiedi, Mahboobeh, Sayyadnejad and Mohammad Ali, "Synthesis of $\mathrm{ZnO}$ Nanoparticles by Spray Pyrolysis Method", Iran. J. Chem. Chem. Eng. Vol. 30, No. 1, (2011).

14. .Rajesh Kumar Shah, Forishmeeta Boruah and Nikahat Parween, "Synthesis and Characterization of $\mathrm{ZnO}$ Nanoparticles using Leaf Extract of Camellia sinesis and Evaluation of their Antimicrobial Efficacy, ISSN: 2319-7706, Vol. 4, pp. 444-450, (2015). 